Case Report

\title{
Anaesthesia management in a child with Apert syndrome with craniosynostosis
}

\author{
Leena Harshad Parate ${ }^{1}$, M. C. Nagaraj ${ }^{2}$ \\ ${ }^{1}$ Assistant professor, ${ }^{2}$ professor, Department of Anaesthesia, M.S. Ramaiah Medical Collage, Banagalore \\ *Corresponding Author : Leena Harshad Parate, M.D, Assistant Professor, Department of Anesthesia, M.S. Ramaiah Medical College, \\ Bangalore. E-mail:dr_leenag@yahoo.co.in \\ Received : :18-08-2015 \\ Review Completed : 29-07-2016 \\ Accepted \\ : 17-08-2016 \\ Keywords : Apert syndrome, \\ craniosynostosis, anaesthesia

\section{Abstract :} \\ Apert syndrome is a rare congenial anomaly with multisystem involvement. It is characterized \\ by craniosynostosis, midfacial hypoplasia and global syndactyly. Altered upper and lower airway \\ anatomy, multiple visceral anomalies and multiple repeat surgeries are main anaesthetic \\ challenges. Here we report a case of seven month old child with Apert syndrome who was \\ posted for posterior sagittal anorectoplasty.
}

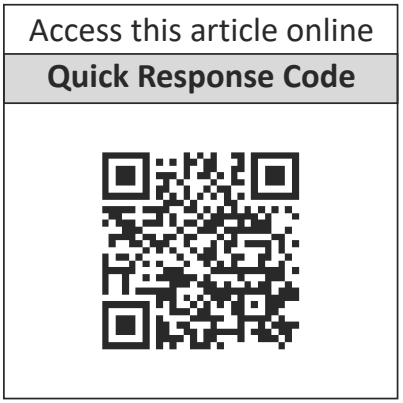

\section{Introduction}

Apert syndrome is a autosomal dominant disease characterized by craniosynostosis, midfacial hypoplasia and global syndactyly. Its incidence is shown to be $15 / 1,000,000$ livebirths and with rare reports from India. ${ }^{[1,2]}$ It may pose multiple anaesthetic challenges due to altered airway anatomy, respiratory system hyper reactivity and multiple visceral anomalies. Here we report a case of seven month old child scheduled for posterior sagittal anorectoplasty procedure for anorectal malformation.

\section{Case Report}

A seven month old female child weighing five $\mathrm{kg}$ was scheduled for posterior sagittal anorectoplasty. She was a known case of Craniosynostosis with type III Apert syndrome. Child was born full term through caesarean section. Mother had gestation diabetes mellitus and child was born with birth weight of $3.5 \mathrm{~kg}$. She underwent sigmoid colostomy for imperforate anus on day two of life. She underwent craniosynostosis repair and Ventriculo-
Peritoneal shunt for hydrocephalus at age of five months. Since then she was phenytoin. She had no history of noisy breathing, sleep apnea, cyanosis or chest infection. On examination child was conscious, active and malnourished. She had brachycephaly, flattened occiput, frontal bossing, proptosis, low set ears and depressed nasal bridge (Figure 1\&2). On airway examination child had large tongue with mallampati grade II and short neck. Bilateral hypoplasia of all digits of all four limbs were noted (Type III Apert syndrome) (Figure 3). Her systemic examination and haematological investigations were normal. Her Computerised Tomography scan of brain showed craniosynostosis of bilateral coronal sutures with brachyturricephaly (premature closure of coronal suture leading to abnormal vertical height of the skull) with no midline shift of structures. Her 2D echo was normal except for moderate atrial septaldefect with left to right shunt. She was accepted as ASAIII status and high risk,informed consent was taken from parents. 
Child was kept nil by mouth six hours before surgery. All routine monitors (ECG, NIBP, SpO2, temperature) were attached. She was premedicated with IV atropine $0.02 \mathrm{ug} / \mathrm{kg}$. Various sizes of tracheal tubes, laryngeal masks, laryngoscopic blades and stylets were kept ready anticipating difficult airway. Anaesthesia was induced with thiopentone $5 \mathrm{mg} / \mathrm{kg}$, fentany $2 \mathrm{ug} / \mathrm{kg}$. Adequate mask ventilation was confirmed with oral airway. Muscle relaxation was achieved with atracurium $0.5 \mathrm{mg} / \mathrm{kg}$. The Cormac-Lehane view was grade II. Airway was secured with plain ETT size 4.0. Anaesthesia was maintained with oxygen, air and sevoflurane. She was kept warm by active warming blanket and eyes were adequately covered. Surgery was done in prone position. Intraoperative fluid and blood loss was replaced with crystalloid. Surgery lasted for two hours and was uneventful. She was reversed with neostigmine and glycopyrrolate. After she regained consciousness and started breathing spontaneously she was extubated. She was shifted to PICU for further observation.

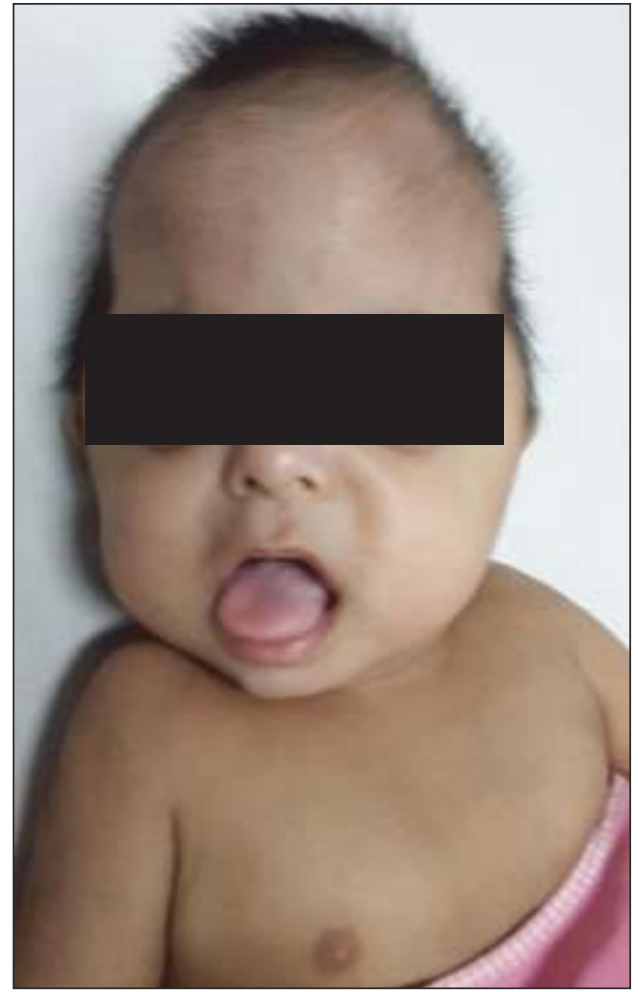

Figure 1 : Figure showing brachycephaly, midfacial hypoplasia, proptosis

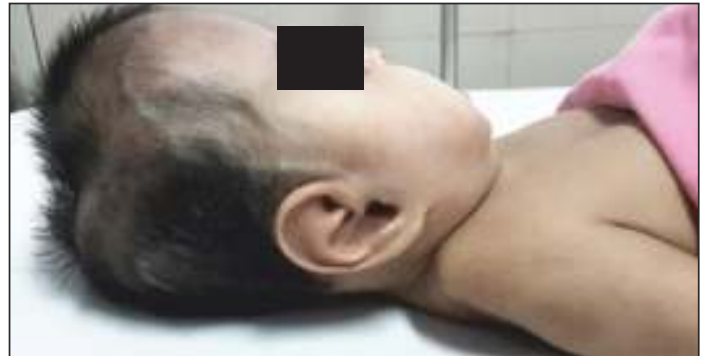

Figure 2 : Figure showing flattened occiput, short neck

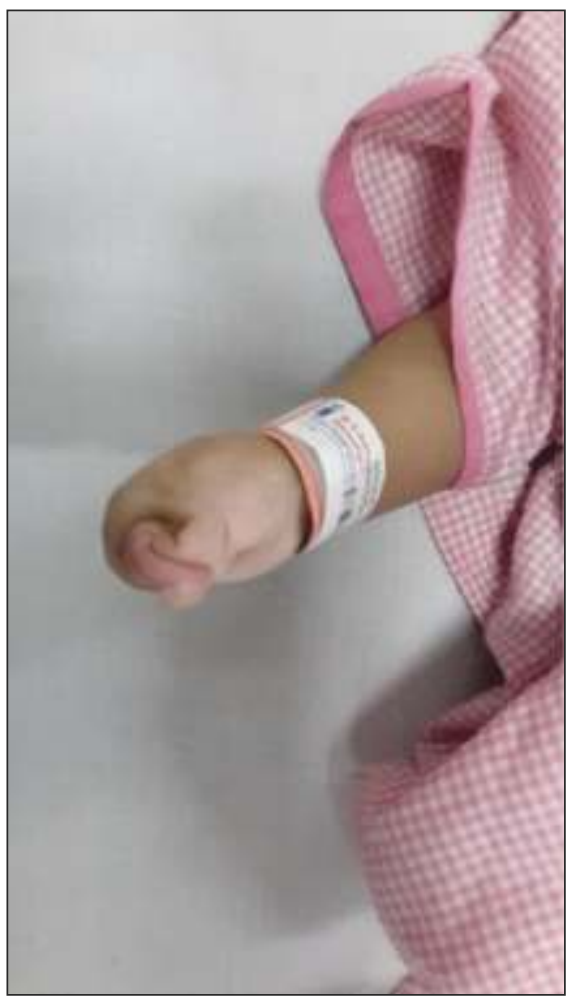

Figure 3 : Figure showing syndactaly (Type III Apert syndrome)

\section{Discussion}

Apert Syndrome was named after the French paediatrician Eugene Apert, who first reported its features in $1906 .{ }^{[3]}$ It is caused by mutation in the Fibroblast growth factor 2 gene. It primarily affects cranium and digit resulting in premature closure of cranial sutures and fusion of digits. Neurological sequelae are due to altered cranial volume and restriction of brain growth. ${ }^{[4]}$

The cardiovascular and genitourinary anomalies are present in $10 \%$ of the patients. ${ }^{[5]}$ Among genitourinary system hydronephrosis is found in $3 \%$ of patients. Children with signs of airway obstruction may warrant a Magnetic Resonance Scan of trachea to rule out tracheal 
abnormality.

The major airway abnormality is midfacialhypoplasia which make them more prone for obstructive sleep apnoea and thus difficult mask ventilation. Use of oral airway, supraglottic airway devices, judicious use of narcotics and sedatives is advisable to avoid airway obstruction during induction and emergence of anaesthesia. About $71 \%$ of Apert children have complex fusion of C5-C6 spine. ${ }^{[6]}$ It may cause difficulty in intubation. In paediatric patients airway assessment, performing fiberopticand retrograde intubation is challenging. In case of children with no previous anaesthesia exposure, an inhalational technique with avoidance of neuromuscular blocker is advisable till definitive airway is secured. Cartilaginous abnormality of trachea, tracheal stenosis, choanal atresia and inability to clear airway secretions leads to significant rise in airway morbidity in these patients. ${ }^{[7]}$ These children tend to have profuse airway secretions making them more prone for bronchospasm. In an emergency situation it may require reintubation. ${ }^{[8]}$ Although preoperative elective nebulization is not justified, monitoring of airway pressure is essential. In our case we premedicated the child with iv atropine to supress the airway secretions. As the surgery was carried in prone position continuous airway pressure

\section{References}

1. Cohe $\mathrm{n}$ MM Jr, Kreiborg S. New indirect method for estimating the birth prevalence of the Apert syndrome. Int J Oral MaxillofacSurg 1992;21:107-9.

2. Sohi BK, Sohi AS. Apert's syndrome. Indian J DermatolVenereolLeprol 1980;46:169-72.

3. Harper JI. Genetics and genodermatoses. In: Champion RH, Burton JL,Burns D, Breathnach SM, editors. Rook/Wilkinson/Ebling Textbook of dermatology. 6th ed. Oxford: Blackwell Science; 1998. p. 425-6.

4. Anantheswar Y.N. and Venkataramana N.K. Pediatric craniofacial surgery for craniosynostosis: Our experience and current concepts: Part-1 J PediatrNeurosci. 2009 Jul-Dec; 4(2): 86-99.

5. Cohen MM Jr, Kreiborg S. Visceral anomalies in the Apert syndrome. Am J Med Genet 1993;45:758-60

6. Hemmer KM, McAlister WH, Marsh JL. Cervical spine anomalies in the craniosynostosis syndromes. Cleft Palate J 1987;24:328-33

7. Cohen MM Jr, Kreiborg S. Upper and lower airway compromise in the Apert syndrome. Am J Med Genet 1992;44:90-3.

8. Basar H, Buyukkocak U, Kaymak C, Akpinar S, SertO,Vargel I. An intraoperative unexpected respiratory problem in a patient with Apert syndrome. Minerva Anestesiol 2007;73:603-6.

9. Kumar N, Arora S, Bindra A, GoyalK.Anesthetic management of craniosynostosis repair in patient with Apert syndrome. Saudi J Anaesth 2014;8:399-401. monitoring was done.Patients can have elevated intracranial pressure, in which case precautions should be taken to avoid further elevation of ICP. Excessive premedication and intraoperative hypoventilation may exacerbate pre-existing increases in ICP.

Another challenge is a difficult intravenous access as these children come frequently for various procedure. Syndactyly also limit cannulation and pulse oximetry monitoring. For short procedure intravenous access can be avoided while in emergency situation intraosseous or intramuscular route can be used. Surgeries involving extensive blood loss may require central venous catheter insertion. ${ }^{[9]}$ These children are more prone for hypothermia as there is a tendencyfor excessive sweating, hence all precaution to maintain normothermia and temperature monitoring is essential. As proptosis and inadequate eye closure could result in eye injury, adequate lubrication and eye padding should be done.

\section{Conclusion}

Apert syndrome is characterized by severe airway and systemic malformation. Thorough screening to rule out visceral anomalies is essential. Great attention and careful preoperative planning is must when such children present for various surgeries. 